\title{
Neurofilamentopathy in Neurodegenerative Diseases
}

\author{
Quan Liu ${ }^{1}$, Fang Xie ${ }^{2}$, Abdiel Alvarado-Diaz ${ }^{3}$, Mark A. Smith ${ }^{4}$, Paula I. Moreira ${ }^{5}$, Xiongwei Zhu ${ }^{4}$ \\ and George Perry*,6
}

${ }^{1}$ School of Dental Medicine, University of Pennsylvania, Philadelphia, PA, USA

${ }^{2}$ Department of Neuroscience, School of Medicine, UCSD, La Jolla, CA, USA

${ }^{3}$ Department of Biological Sciences, Universidad Autonoma de Nuevo Leon, Nuevo Leon, Mexico

${ }^{4}$ Department of Pathology, Case Western Reserve University, Cleveland, OH, USA

${ }^{5}$ Center for Neuroscience and Cell Biology, University of Coimbra, Coimbra, Portugal

${ }^{6}$ College of Sciences, University of Texas at San Antonio, San Antonio, TX, USA

\begin{abstract}
Neurofilament protein alterations are found in many neurodegenerative diseases, such as amyotrophic lateral sclerosis, Parkinson, Alzheimer, and Charcot-Marie-Tooth. Abnormal modifications of neurofilament, such as mutation, oxidation and phosphorylation, are linked to the disease-related alteration. In this review, the most recent discovery and central arguments about functions, pathological modifications, and genetic mutations related to neurofilaments in neurodegenerative diseases is presented.
\end{abstract}

Keywords: Neurofilament, Alzheimer disease, Parkinson disease, Amyotrophic lateral sclerosis, Phosphorylation, Oxidation, Glycosylation.

\section{INTRODUCTION}

Neurofilaments are intermediate filaments in neurons composed of three subunits, NFH, NFM, and NFL (Neurofilament heavy, medium, and light subunits). Primarily expressed in neurons, neurofilament proteins are major components in large myelinated axons, e.g. sciatic and optic nerves. Abnormal accumulation of neurofilament is a primary finding in many human neurodegenerative disorders, including amyotrophic lateral sclerosis, Parkinson, Alzheimer, Charcot-Marie-Tooth, dementia with Lewy bodies $[1,2]$, and toxic neuropathy [3]. Many alterations can potentially lead to accumulation of neurofilaments, including mutation, disregulation of neurofilament protein synthesis, defective axonal transport, and abnormal phosphorylation/glycosylation/ oxidation [4]. Neurofilament abnormality in neurodegenerative disorders is a hallmark of neuronal dysfunction, especially marking axonal degeneration.

\section{Amyotrophic Lateral Sclerosis (ALS)}

A major pathological hallmark of ALS is intraneuronal accumulation of phosphorylated neurofilament proteins in degenerating motor neurons [5-7]. The neurofilament protein accumulations are characterized by forming initially in the distal axon and retrogradly transported to the cell body, correlated with severity of disease. Neurofilament gene expression patterns are altered in ALS, suggesting NF subunit ratio could be important [8].

Singly overexpressing any of the neurofilament subunits (NFL, NFM or NFH) in transgenic mice led to prominent

*Address correspondence to this author at the University of Texas at San Antonio, One UTSA Circle, San Antonio, Texas 78249, USA; Tel: 210-4584450; Fax: 210-458-4445; E-mail: george.perry@utsa.edu motor neuropathy characterized by the presence of abnormal neurofilament accumulations resembling those found in ALS [9-11]. Restoring a correct stoichiometry of human NFL to NF-H subunits with the co-expression of human NFL transgene in transgenic mice overexpressing human NFH rescues the motor neuropathy [12]. Similar changes in stoichometry may occur in diseases as NFL mRNA is selectively reduced by up to $70 \%$ in degenerating neurons of ALS and AD [13, 14].

Codon deletions or insertions in the KSP regions of NFH have been detected in a small number of sporadic cases of ALS, including a large deletion of five KSP repeats [15-17].

Studies by Lobsiger and colleagues [18] showed genetic elimination of NFM and NFH tail domains and their 58 known phosphorylation sites in SOD1 mutant mice accelerates aberrant phosphorylation of other neuronal substrates while leaving overall neurofilament content unaltered. The disease onset is significantly delayed and survival is extended in mice, which indicates that abnormal phosphorylation may be a detrimental factor.

Studies by Ludemann et al., [19] showed that in spinal cord tissue of a transgenic rat model for ALS, O-linked Nacetylglucosamine immunoreactivity of neurofilament proteins is strongly decreased compared with wild-type animals while phosphorylation is increased, suggesting competition of the binding sites of these two modifications and a potential mechanism for the formation of neurofilament protein accumulations in ALS.

Pin 1 associates with phosphorylated NFH in neurons and is colocalized in ALS-affected spinal cord neuronal inclusions [20]. Inhibition of Pin1 activity by inhibitor or downregulating Pin1 levels through siRNA rescued neurons from 
glutamate-induced cell death. The authors suggest that Pin 1 inhibition may be a therapeutic target to reduce pathological accumulations of $\mathrm{p}-\mathrm{NFH}$

More recently, the possible involvement of dynein/ dynactin in ALS has also been explored. Teuling and colleagues [21] generated transgenic mice with neuron specific expression of Bicaudal D2 N-terminus (BICD2-N) to chronically impair dynein/dynactin function and their results showed that BICD2-N mice did not develop signs of motor neuron degeneration and motor abnormalities even with apparent abnormalities. Also this transgene increased life span in SOD1-G93A ALS transgenic mice. They concluded that impaired dynein/dynactin function may be part of the ALS phenotype although further work is clearly called for to clarify the mechanism.

Cheroni and colleagues [22] demonstrated impairment of the ubiquitin proteasome system (UPS) in lumbar spinal cord in double transgenic mice expressing the familial ALS superoxide dismutase 1 (SOD1) gene mutation G93A (SOD1G93A). They showed that one third of the cells with accumulation of the UPS reporter substrate also displayed an accumulation of phosphorylated neurofilaments (SM1-31), like those normally present only in axons. In line with this, they report that not all the ventral horn neurons showing reporter gene immunoreactivity also accumulated phosphorylated neurofilaments or ubiquitin, two markers of degeneration in ALS.

The possibility that not only post-translational changes of NF subunits are promoting neurofilamentopathy has also been addressed. Volkening and colleagues [23] examined the interactions of TDP-43, 14-3-3 and SOD1 proteins with NFL mRNA 3'UTR due to their potential to directly affect the stability of NFL transcripts. When ALS spinal cord motor neurons were assessed, it appeared that TDP-43 can be sequestered into translationally quiescent granules as either stress and degradative granules in a manner consistent with the relocalization of TDP-43 under neuronal stress. Their findings suggest that a greater proportion of NFL may be targeted for translational silencing and/or degradation in ALS. Interestingly, mice lacking neurofilament expression show delayed disease onset from mutant SOD1 [24].

Brettschneider and colleagues [25] reported a 5-fold increase of NFH level in CSF samples of ALS patients compared to controls, suggesting NFH level can be a marker of axonal damage. Kuhle and collaborators [26] validated a new electrochemiluminescence (ECL) immunoassay for the neurofilament heavy chain protein using SMI-35 antibody, showing that their ECL based assay resulted in superior sensitivity, precision and accuracy, further opening the field to neurofilament-based biomarkers.

\section{Alzheimer Disease (AD)}

Neurofibrillary tangles, one of the hallmarks of AD, are composed of abnormally modified tau protein, plus neurofilament proteins, ubiquitin and other cytoskeleton proteins $[27,28]$. Studies agree that tau protein and neurofilament proteins found in neurofibrillary tangles are extensively phosphorylated, especially in some sites not seen in the physiological state, which is likely due to perturbation in the balance between kinase and phosphatase activities [29-32].
Neurofilament protein expression levels are altered in $\mathrm{AD}$ [33]. In addition, oxidative markers are highly concentrated in the lesions of $\mathrm{AD}$ and in neurofilament proteins of axons whether in AD or controls [34-36]. Pamplona and colleagues [36] showed elevation of all markers of oxidation, particularly those of reactive aldehydes from glycoxidation and lipoxidation that react with lysine residues on proteins in brain cortex samples from Alzheimer patients using GCmass spectrometry. Modifications involve neurofilaments, tubulin, and others.

The presence of neurofilament proteins and their phosphorylation sites in neurites of senile plaques were also examined [37], where they show novel phosphorylation sites on NFL. They suggest the complexity and possible role of the neurofilament in the formation of senile plaques.

Deng and colleagues [38] demonstrated that OGlcNAcylation and phosphorylation of NFM regulate each other reciprocally in cultured neuroblastoma cells and in metabolically active rat brain slices. In animal models of fasting rats, they found a decrease in O-GlcNAcylation and increase in phosphorylation of NFM. They also observed decreased O-GlcNAcylation and an increased phosphorylation of NFM in AD brain. These results suggest that $\mathrm{O}$ GlcNAcylation and phosphorylation of NF-M were regulated reciprocally and that the hyperphosphorylation and accumulation of NF-M in AD brain might be caused by impaired brain glucose uptake/metabolism via down-regulation of NFM O-GlcNAcylation.

Björkdahl and colleagues [39] showed that overexpression of the chaperonin proteins Hsp27 or alphaB-crystallin in $\mathrm{N} 2$ a cells could increase or decrease phosphorylation level of tau and NF. Expression of Hsp27 and alphaB-crystallin in AD brain samples were increased by $20 \%$ and $30 \%$ respectively, which correlated significantly with phosphorylated tau and NF proteins.

Using ELISA and antibodies to tau and NFH, Brettschneider and colleagues [25] reported that NFH protein increased 10 fold in AD patient CSF samples compared to controls. They suggested that NFH level in CSF could be used as a marker for axonal damage, much as tau has been suggested as a marker for neuronal damage.

The role of neurofibrillary tangles and senile plaques in $\mathrm{AD}$ is under intensive debate [40]. Some researchers believe that protein accumulation in various polymeric and monomeric forms is the initial cause of the disease, and others think such accumulation is the response to the initial insult, which results in different approaches in development of therapeutics. Significant protein accumulation is a response to oxidative damage occurring with aging, [35, 41]. Therefore, preventing oxidative damage may provide a useful intervention to reduce neurofilament protein abnormalities.

Recently, Thangavel [42] and collaborators described a negative relation between SMI-32 immunoreactivity, nonphosphorylated neurofilament, and AT8, an antibody against hyperphosphorylated tau, in specific brain areas. Neurons expressing non-phosphorylated neurofilaments in temporal cortical areas were susceptible to early degeneration in AD and the vulnerability of these SMI32 positive subpopulations of pyramidal cells in AD is associated with co-expression of abnormally phosphorylated tau protein, suggesting a com- 
plex interplay between tau and neurofilament phosphorylation $[43,44]$.

Knowing the distribution and co-localization of other neurofilament-related proteins is also important to understanding the neurofilamentopathy in AD. Sonoda and colleagues [45] demonstrated the phosphatase and tensin homologue on chromosome 10 (PTEN), linked to AD, functions both as a tyrosine phosphatase and lipid phosphatase and is colocalized with abnormal tau and phosphorylated neurofilament proteins in neurons. These findings suggest that redistribution of PTEN to neuritic pathology may be significant in the formation of tau and neurofilament pathology in AD brains.

\section{Parkinson Disease (PD)}

PD is marked by degeneration of the pigmented neurons in the substantia nigra resulting in decreased dopamine secretion. Lewy bodies, the major pathological change of PD, and found in the degenerating neurons, are an inclusion composed of numerous proteins including $\alpha$-synuclein, three neurofilament subunits, ubiquitin and proteasome subunits, torsinA and parkin [46, 47], some of which are genetically linked to the disease [48-51].

A proteomic analysis of substantia nigra samples from PD patients showed reduced protein level of NFM and NFL in brain of PD patients, and an elevated oxidative-state cellular environment was also confirmed [52]. NFL mRNA is also decreased, correlating with the severity of the disease of PD [53].

An early onset (age 16) PD patient showed a point mutation in the region of the NEFM gene coding for the rod domain 2B of NFM [54]. The base pair change results in substitution of serine for glycine at residue 336, and was argued to disrupt neurofilament assembly [55]. This NFEM gene mutation was screened in another $322 \mathrm{PD}$ patients and none were found [56]. Han and colleagues [57] re-screened an additional 102 PD patients and 45 controls for this single base pair substitution (G1747A) mutation of the NFEM gene, which was reported by Lavedan and colleagues [54]. No mutation was found.

Abdo and colleagues [58] examined the differences of patients with idiopathic Parkinson's disease from patients with multiple system atrophy predominated by parkinsonism (MSA-P) using multiple protein markers. They showed that CSF levels of NFL, NFH, and tau were significantly increased in MSA-P.

\section{Charcot-Marie-Tooth Disease (CMT)}

CMT is the most common inherited neurological disorder and it is generally inherited in an autosomal dominant pattern. CMT affects both motor neurons and sensory neurons to the muscles, and patients slowly lose function of their feet/legs and hands/arms as nerves to the extremities degenerate.

Several mutations of the NEFL gene on chromosome 8 are associated with CMT2 including a proline to glutamine at residue 8 , a proline-to-serine substitution at codon 22 , leucine to proline at residue 333 , leucine to proline at residue 394 [59-64]. Jordanova and colleagues [62] also found six pathogenic missense mutations and one 3-bp inframe dele- tion in the NFL gene in 323 patients with different CMT phenotypes.

Recently, Sasaki and colleagues [65] showed that Pro22Ser mutations abolished Thr21 phosphorylation by cyclin-dependent kinase 5 and external signal regulated kinase, which suppressed filament assembly, but phosphorylation by protein kinase A (PKA) inhibited aggregate formation in vitro and alleviated aggregates in cortical neurons. These results indicate that the Pro22Ser CMT mutation induces abnormal filament accumulation by disrupting proper oligomer formation and the aggregates are mitigated by phosphorylation with PKA, which makes it a viable target for the development of therapeutics.

Further examination of three mutations in the NFL gene P22S, P8R, Q333P, in cell culture, [66] showed these mutations affect the axonal transport of mutant and wild-type neurofilaments. They also affected the transport of mitochondria and human amyloid $\beta$ protein precursor; resulting in alterations of retrograde axonal transport, fragmentation of the Golgi apparatus, and increased neuritic degeneration.

Zhai and colleagues [67] investigated the role of aggregation of NFL protein in the neurotoxicity of CMT mutant NFL and CMT mutant HSPB1 in motor neurons, which cause neuron death. They found that expression of wild type HSPB1 could remediate the progressive degeneration and loss of neuronal viability. Hull and colleagues [68], using a mouse muscle cell line expressing chimeric neurofilament (NF) proteins, found reduced cell viability and activated caspases, which mimic the pathology of CMT and may be a useful cell model for future studies to investigate the mechanism responsible for NFL disruption. These studies support the view that aggregation of NFL is a common triggering event of motor neuron degeneration in CMT.

Moreover, Zhu and colleagues [69] described how both increases and decreases in the phosphorylation of neurofilament network are modulated by multisynthetase complex p43 (MSC p43). Their results determine that overexpression of MSC p43 led to a decreased level of neurofilament protein phosphorylation, whereas MSC p43 depletion caused hyperphosphorylation of neurofilament proteins and neurofilament network disassembly in primary cultured neurons and motor axons. Further assays using MSC p43-Null mice show similar phenotypic traits shared with CMT neuropathy type 2D, such as loss of large diameter axons from both motor and sensory peripheral nerves, distal motor neuropathy with impairment in synaptic connectivity at neuro-muscular junctions, and muscle denervation in the hind limb.

The role of neurofilaments was further clarified by using double transgenic mice, hNF-L ${ }^{\mathrm{P} 22 \mathrm{~S}}$; that model CMT2E [70]. They suggest CMT pathology is mostly unrelated to the NF accumulation in the cell bodies, as they found normal NF density in axons but instead decreased density of microtubules. The effects of hNF-L ${ }^{\mathrm{P} 22 \mathrm{~S}}$ could arise from cytoskeletal alterations that provoke axonal transport defects due to microtubule abnormalities. These findings highlight the close interrelationship of cytoskeletal systems.

\section{SUMMARY}

Neurofilament abnormalities have been directly or indirectly demonstrated in multiple neurodegerative diseases. 
The removal of the protein aggregates with different approaches is an area of intense interest. In spite of whether these protein aggregates were the cause or the consequence of these diseases, neurofilament abnormalities are a critical factor in the cellular disruption in a number of neurodegenerative diseases. Understanding the characteristics, the mechanism of the formation, and approaches to modulate neurofilament abnormalities is central to monitoring and developing efficacious therapeutics.

\section{REFERENCES}

[1] Liu Q, Xie F, Siedlak SL, et al. Neurofilament proteins in neurodegenerative diseases. Cell Mol Life Sci 2004; 61: 3057-75.

[2] Al-Chalabi A, Miller CC. Neurofilaments and neurological disease. Bioessays 2003; 25: 346-55.

[3] Zhu Q, Lindenbaum M, Levavasseur F, Jacomy H, Julien JP. Disruption of the NF-H gene increases axonal microtubule content and velocity of neurofilament transport: relief of axonopathy resulting from the toxin beta, betac-iminodipropionitrile. J Cell Biol 1998; 143: 183-93.

[4] Dong DL, Xu ZS, Chevrier MR, Cotter RJ, Cleveland DW, Hart GW. Glycosylation of mammalian neurofilaments. Localization of multiple O-linked N-acetyl-glucosamine moieties on neurofilament polypeptides L and M. J Biol Chem 1993; 268: 16679-87.

[5] Manetto V, Sternberger NH, Perry G, Sternberger LA, Gambetti P. Phosphorylation of neurofilaments is altered in amyotrophic lateral sclerosis. J Neuropathol Exp Neurol 1988; 47: 642-53.

[6] Leigh PN, Dodson A, Swash M, Brion JP, Anderton BH. Cytoskeletal abnormalities in motor neuron disease. An immunocytochemical study. Brain 1989; 112: 521-35.

[7] Murayama S, Bouldin TW, Suzuki K. Immuno-cytochemical and ultrastructural studies of upper motor neurons in amyotrophic lateral sclerosis. Acta Neuropathol 1992; 83: 518-24.

[8] Bergeron C, Beric-Maskarel K, Muntasser S, Weyer L, Somerville MJ, Percy ME. Neurofilament light and polyadenylated mRNA levels are decreased in amyotrophic lateral sclerosis motor neurons. J Neuropathol Exp Neurol 1994; 53: 221-30.

[9] Xu Z, Cork LC, Griffin JW, Cleveland DW. Increased expression of neurofilament subunit NF-L produces morphological alterations that resemble the pathology of human motor neuron disease. Cell 1993; 73: 23-33.

[10] Wong PC, Marszalek J, Crawford TO, et al. Increasing neurofilament subunit NF-M expression reduces axonal NF-H, inhibits radial growth, and results in neurofilamentous accumulation in motor neurons. J Cell Biol 1995; 130: 1413-22.

[11] Cote F, Collard JF, Julien JP. Progressive neuronopathy in transgenic mice expressing the human neurofilament heavy gene: a mouse model of amyotrophic lateral sclerosis. Cell 1993; 73: 3546.

[12] Meier J, Couillard-Despres S, Jacomy H, Gravel C, Julien JP. Extra neurofilament NF-L subunits rescue motor neuron disease caused by overexpression of the human NF-H gene in mice. J Neuropathol Exp Neurol 1999; 58: 1099- 110.

[13] Wong NK, He BP, Strong MJ. Characterization of neuronal intermediate filament protein expression in cervical spinal motor neurons in sporadic amyotrophic lateral sclerosis (ALS). J. Neuropathol Exp Neurol 2000; 59: 972-82.

[14] Menzies FM, Grierson AJ, Cookson MR, et al. Selective loss of neurofilament expression in $\mathrm{Cu} / \mathrm{Zn}$ superoxide dismutase (SOD1) linked amyotrophic lateral sclerosis. J Neurochem 2002; 82: 111828.

[15] Figlewicz DA, Krizus A, Martinoli MG, et al. Variants of the heavy neurofilament subunit are associated with the development of amyotrophic lateral sclerosis. Hum Mol Genet 1994; 3: 1757-61.

[16] Tomkins J, Usher P, Slade JY, et al. Novel insertion in the KSP region of the neurofilament heavy gene in amyotrophic lateral sclerosis (ALS). Neuroreport 1998; 9: 3967-70.

[17] Al-Chalabi A, Andersen PM, Nilsson P, et al. Deletions of the heavy neurofilament subunit tail in amyotrophic lateral sclerosis. Hum Mol Genet 1999; 8: 157-64.

[18] Lobsiger CS, Garcia ML, Ward CM, Cleveland DW. Altered axonal architecture by removal of the heavily phosphorylated neurofilament tail domains strongly slows superoxide dismutase $1 \mathrm{mu}-$ tant-mediated ALS. Proc Natl Acad Sci USA 2005; 102: 10351-6.
[19] Ludemann N, Clement A, Hans VH, Leschik J, Behl C, Brandt R. O-glycosylation of the tail domain of neurofilament protein $\mathrm{M}$ in human neurons and in spinal cord tissue of a rat model of amyotrophic lateral sclerosis (ALS). J Biol Chem 2005; 280: 31648-58.

[20] Kesavapany S, Patel V, Zheng YL, et al. Inhibition of Pin1 reduces glutamate-induced perikaryal accumulation of phosphorylated neurofilament-H in neurons. Mol Biol Cell 2007; 18: 364555 .

[21] Teuling E, van Dis B, Wulf PS, et al. A novel mouse model with impaired dynein/dynactin function develops amyotrophis lateral sclerosis (ALS)-like features in motor neurons and improves lifespan in SOD1-ALS mice. Hum Mol Genet 2008; 17: 2849-62.

[22] Cheroni C, Marino M, Tortarolo M, et al. Functional alterations of the ubiquitin-proteasome system in motor neurons of a mouse model of familial amyotrophic lateral sclerosis. Hum Mol Genet 2009; 18: 82-96.

[23] Volkening K, Leystra-Lantz C, Yang W, Jaffee H, Strong MJ. Tar DNA binding protein of $43 \mathrm{kDa}$ (TDP-43), 14-3-3 proteins and copper/zinc superoxide dismutase (SOD1) interact to modulate NFL mRNA stability. Implications for altered RNA processing in amyotrophic lateral sclerosis (ALS). Brain Res 2009; 1305: 168-82.

[24] Williamson TL, Bruijn LI, Zhu Q, et al. Absence of neurofilaments reduces the selective vulnerability of motor neurons and slows disease caused by a familial amyotrophic lateral sclerosislinked superoxide dismutase 1 mutant. Proc Natl Acad Sci USA 1998; 95: 9631-6.

[25] Brettschneider J, Petzold A, Sussmuth SD, Ludolph AC, Tumani $\mathrm{H}$. Axonal damage markers in cerebrospinal fluid are increased in ALS. Neurology 2006; 66: 852-6.

[26] Kuhle J, Regeniter A, Leppert D, et al. A highly sensitive electrochemiluminescence immunoassay for the neurofilament heavy chain protein. J Neuroimmunol 2010; 220: 114-9.

[27] Perry G, Rizzuto N, Autilio-Gambetti L, Gambetti P. Paired helical filaments from Alzheimer disease patients contain cytoskeletal components. Proc Natl Acad Sci USA 1985; 82: 3916-20.

[28] Perry G, Friedman R, Shaw G, Chau V. Ubiquitin is detected in neurofibrillary tangles and senile plaque neurites of Alzheimer disease brains. Proc Natl Acad Sci USA 1987; 84: 3033-6.

[29] Gong CX, Lidsky T, Wegiel J, Zuck L, Grundke-Iqbal I, Iqbal K. Phosphorylation of microtubule-associated protein tau is regulated by protein phosphatase $2 \mathrm{~A}$ in mammalian brain. Implications for neurofibrillary degeneration in Alzheimer's disease. J Biol Chem 2000; 275: 5535-44.

[30] Trojanowski JQ, Mawal-Dewan M, Schmidt ML, Martin J, Lee VM. Localization of the mitogen activated protein kinase ERK2 in Alzheimer's disease neurofibrillary tangles and senile plaque neurites. Brain Res 1993; 618: 333-7.

[31] Maccioni RB, Otth C, Concha II, Munoz JP. The protein kinase Cdk5. Structural aspects, roles in neurogenesis and involvement in Alzheimer's pathology. Eur J Biochem 2001; 268: 1518-27.

[32] Mandelkow EM, Drewes G, Biernat J, et al. Glycogen synthase kinase-3 and the Alzheimer-like state of microtubule-associated protein tau. FEBS Lett 1992; 314: 315-21.

[33] McLachlan DR, Lukiw WJ, Wong L, Bergeron C, Bech-Hansen NT. Selective messenger RNA reduction in Alzheimer's disease. Brain Res 1988; 427: 255-61.

[34] Wataya T, Nunomura A, Smith MA, et al. High molecular weight neurofilament proteins are physiological substrates of adduction by the lipid peroxidation product hydroxynonenal. J Biol Chem 2002; 277: 4644-8.

[35] Liu Q, Raina AK, Smith MA, Sayre LM, Perry G. Hydroxynonenal, toxic carbonyls, and Alzheimer disease. Mol Aspects Med 2003; 24: 305-13.

[36] Pamplona R, Dalfo E, Ayala V, et al. Proteins in human brain cortex are modified by oxidation, glycoxidation, and lipoxidation. Effects of Alzheimer disease and identification of lipoxidation targets. J Biol Chem 2005; 280: 21522-30.

[37] Liao L, Cheng D, Wang J, et al. Proteomic characterization of postmortem amyloid plaques isolated by laser capture microdissection. J Biol Chem 2004; 279: 37061-8.

[38] Deng Y, Li B, Liu F, et al. Regulation between O-GlcNAcylation and phosphorylation of neurofilament-M and their dysregulation in Alzheimer disease. FASEB J 2008; 22: 138-45.

[39] Bjorkdahl C, Sjögren MK, Zhou X, et al. Small heat shock proteins Hsp27 or alphaB-crystallin and the protein components of 
neurofibrillary tangles: tau and neurofilaments. J Neurosci Res 2008; 86: 1343-52.

[40] Mayeux R, Honig LS, Tang MX, et al. Plasma A[beta]40 and A[beta] 42 and Alzheimer's disease: relation to age, mortality, and risk. Neurology 2003; 61: 1185-90.

[41] Lee HG, Perry G, Moreira PI, et al. Tau phosphorylation in Alzheimer's disease: pathogen or protector? Trends Mol Med 2005; 11: 164-9.

[42] Thangavel R, Sahu SK, Van Hoesen GW, Zaheer A. Loss of nonphosphorylated neurofilament immunoreactivity in temporal cortical areas in Alzheimer's disease. Neuroscience 2009; 160: 427-33.

[43] Yang X, Yang Y, Lou Y, Li G, Wang J, Yang ES. Hyperphosphorylation and accumulation of neurofilament proteins in transgenic mice with Alzheimer presenilin 1 mutation. Cell Mol Neurobiol 2009; 29: 497-501.

[44] Ahlijanian MK, Barrezueta NX, Williams RD, et al. Hyperphosphorylated tau and neurofilament and cytoskeletal disruptions in mice overexpressing human p25, an activator of cdk5. Proc Natl Acad Sci USA 2000; 97: 2910-5.

[45] Sonoda Y, Mukai H, Matsuo K, et al. Accumulation of tumorsuppressor PTEN in Alzheimer neurofibrillary tangles. Neurosci Lett 1996; 471: 20-4.

[46] Galloway PG, Mulvihill P, Perry G. Filaments of Lewy bodies contain insoluble cytoskeletal elements. Am J Pathol 1992; 140: 809-22.

[47] Trimmer PA, Borland MK, Keeney PM, Bennett JP Jr, Parker WD Jr. Parkinson's disease transgenic mitochondrial cybrids generate Lewy inclusion bodies. J Neurochem 2004; 88: 800-12.

[48] Abbas N, Lucking CB, Ricard S, et al. A wide variety of mutations in the parkin gene are responsible for autosomal recessive parkinsonism in Europe. French Parkinson's Disease Genetics Study Group and the European Consortium on Genetic Susceptibility in Parkinson's Disease. Hum Mol Genet 1999; 8: 567-74.

[49] Leroy E, Anastasopoulos D, Konitsiotis S, Lavedan C, Polymeropoulos MH. Deletions in the Parkin gene and genetic heterogeneity in a Greek family with early onset Parkinson's disease. Hum Genet 1998; 103: 424-7.

[50] Lucking CB, Durr A, Bonifati V, et al. Association between earlyonset Parkinson's disease and mutations in the parkin gene. French Parkinson's Disease Genetics Study Group. N Engl J Med 2000; 342: 1560-7.

[51] Lim KL, Dawson VL, Dawson TM. The genetics of Parkinson's disease. Curr Neurol Neurosci Rep 2002; 2: 439-46.

[52] Basso M, Giraudo S, Corpillo D, Bergamasco B, Lopiano L, Fasano M. Proteome analysis of human substantia nigra in Parkinson's disease. Proteomics 2004; 4: 3943-52.

[53] Hill WD, Arai M, Cohen JA, Trojanowski JQ. Neurofilament mRNA is reduced in Parkinson's disease substantia nigra pars compacta neurons. J Comp Neurol 1993; 329: 328-36.

[54] Lavedan C, Buchholtz S, Nussbaum RL, Albin RL, Polymeropoulos MH. A mutation in the human neurofilament M gene in Parkinson's disease that suggests a role for the cytoskeleton in neuronal degeneration. Neurosci Lett 2002; 322: 57-61.

[55] Perez-Olle R, Lopez-Toledano MA, Goryunov D, et al. Mutations in the neurofilament light gene linked to Charcot-Marie-Tooth disease cause defects in transport. J Neurochem 2005; 93: 861-74.
[56] Kruger R, Fischer C, Schulte T, et al. Mutation analysis of the neurofilament M gene in Parkinson's disease. Neurosci Lett 2003; 351: 125-9.

[57] Han F, Bulman DE, Panisset M, Grimes DA. Neurofilament M gene in a French-Canadian population with Parkinson's disease. Can J Neurol Sci 2005; 32: 68-70.

[58] Abdo WF, Bloem BR, Van Geel WJ, Esselink RA, Verbeek MM. CSF neurofilament light chain and tau differentiate multiple system atrophy from Parkinson's disease. Neurobiol Aging 2007; 28: 7427.

[59] Lee MK, Marszalek JR, Cleveland DW. A mutant neurofilament subunit causes massive, selective motor neuron death: implications for the pathogenesis of human motor neuron disease. Neuron 1994; 13: 975-88.

[60] Mersiyanova IV, Perepelov AV, Polyakov AV, et al. A new variant of Charcot-Marie- Tooth disease type 2 is probably the result of a mutation in the neurofilament-light gene. Am J Hum Genet 2000; 67: 37-46.

[61] Georgiou DM, Zidar J, Korosec M, Middleton LT, Kyriakides T, Christodoulou K. A novel NF-L mutation Pro22Ser is associated with CMT2 in a large Slovenian family. Neurogenetics 2002; 4: 93-6.

[62] Jordanova A, De Jonghe P, Boerkoel CF, et al. Mutations in the neurofilament light chain gene (NEFL) cause early onset severe Charcot-Marie-Tooth disease. Brain 2003; 126: 590-7.

[63] Zuchner S, Vorgerd M, Sindern E, Schroder JM. The novel neurofilament light (NEFL) mutation Glu397Lys is associated with a clinically and morphologically heterogeneous type of CharcotMarie-Tooth neuropathy. Neuromuscul Disord 2004; 14: 147-57.

[64] Yoshihara $\mathrm{T}$, Yamamoto $\mathrm{M}$, Hattori $\mathrm{N}$, et al. Identification of novel sequence variants in the neurofilament-light gene in a Japanese population: analysis of Charcot-Marie-Tooth disease patients and normal individuals. J Peripher Nerv Syst 2002; 7: 221-4.

[65] Sasaki T, Gotow T, Shiozaki M, et al. Aggregate formation and phosphorylation of neurofilament-L Pro22 Charcot-Marie-Tooth disease mutants. Hum Mol Genet 2006; 15: 943-52.

[66] Perez-Olle R, Lopez-Toledano MA, Liem RK. The G336S variant in the human neurofilament-M gene does not affect its assembly or distribution: importance of the functional analysis of neurofilament variants. J Neuropathol Exp Neurol 2004; 63: 759-74.

[67] Zhai J, Lin H, Julien JP, Schlaepfer WW. Disruption of neurofilament network with aggregation of light neurofilament protein: a common pathway leading to motor neuron degeneration due to Charcot-Marie-Tooth disease-linked mutations in NFL and HSPB1. Hum Mol Genet 2007; 16: 3103-16.

[68] Hull E, Spoja C, Cordova M, Cohlberg JA. Neurofilament protein aggregation in a cell line model system. Biochem Biophys Res Commun 2008; 366: 73-9.

[69] Zhu X, Liu Y, Yin Y, et al. MSC p43 required for axonal development in motor neurons. Proc Natl Acad Sci USA 2009; 106: 15944-9.

[70] Dequen F, Filali M, Larivière RC, Perrot R, Hisinaga S, Julien J. Reversal of neuropathy phenotypes in conditional mouse model of Charcot-Marie-Tooth disease type 2E. Hum Mol Genet 2010; 19: 2616-29.

Received: June 12, 2011

Revised: July 25, 2011

Accepted: July 28, 2011

(C) Liu et al.; Licensee Bentham Open.

This is an open access article licensed under the terms of the Creative Commons Attribution Non-Commercial License (http://creativecommons.org/licenses/by-nc/3.0/) which permits unrestricted, non-commercial use, distribution and reproduction in any medium, provided the work is properly cited. 